\title{
Universiteit
}

Leiden

The Netherlands

\section{Migratie, vluchtelingen en veiligheid}

Janssen, J.; Leun, J.P. van der; Hemert, D. van

\section{Citation}

Janssen, J., Leun, J. P. van der, \& Hemert, D. van. (2017). Migratie, vluchtelingen en veiligheid. Tijdschrift Voor Veiligheid, 16(2-3), 3-10. doi:10.5553/TvV/187279482017016002001

Version:

Publisher's Version

License: $\quad$ Leiden University Non-exclusive license

Downloaded from: $\quad$ https://hdl.handle.net/1887/57792

Note: To cite this publication please use the final published version (if applicable). 


\title{
REDACTIONEEL
}

\section{Migratie, vluchtelingen en veiligheid}

\author{
Janine Janssen, Joanne van der Leun \& Dianne van Hemert
}

\section{Ontwikkelingen}

Migratie is een internationaal verschijnsel en van alle tijden. Naast binnenlandse migratie is er ook veel migratie over landsgrenzen. Waar West-Europa na de Tweede Wereldoorlog meer een emigratieregio dan een immigratieregio werd, draaide dat gaandeweg om. In Nederland vond de omslag plaats ten tijde van de economische groei eind jaren zestig. Het zou nog lang duren voordat Nederland zich een immigratieland voelde. Beleidsmatig kwam die erkenning pas eind jaren negentig van de vorige eeuw. PvdA-staatssecretaris Aad Kosto stelde begin jaren negentig vast dat Nederland een 'de facto immigratieland' was, 'maar het niet wilde zijn' (de Volkskrant 28 mei 2016). De acceptatie van en het geloof in een multi-etnische samenleving die gaandeweg leek toe te nemen, kreeg een sterke knauw rond de millenniumwisseling. Momenteel is het beeld verre van eenduidig. Enerzijds is de multi-etnische samenleving allang een feit, zeker in de grote steden, anderzijds is er een voortdurend ongemak over migratie en integratie en alles wat daarmee samenhangt, zowel in het politieke als in het bredere maatschappelijke debat (Van Tubergen, 2012). Migratie is daarmee een complex thema dat veel emoties oproept.

De laatste jaren wordt onder andere door de sterke stijging van het aantal asielzoekers vaak gesproken van een migratiecrisis en is ook de link naar binnenlandse veiligheid steeds zichtbaarder. Een recent voorbeeld is de oproep van de burgemeester van Kampen voor een avondklok voor asielzoekers, nadat een ernstig zedendelict was gepleegd door een bewoner van een asielzoekerscentrum. De burgemeester verdedigde deze verregaande oproep met een verwijzing naar de veiligheid van omwonenden en die van de asielzoekers zelf (de Volkskrant 22 mei 2017). Een ander voorbeeld betreft de recente aandacht voor asielzoekers uit landen die op de lijst van veilige landen staan en berichten over hun mogelijke criminele betrokkenheid.

\section{Veiligheid}

Historisch gezien is het niet ongebruikelijk dat een verband wordt gelegd tussen migratie en veiligheid. Het afgelopen decennium is de associatie van migratie met (on)veiligheid, en zelfs nationale veiligheid, echter opmerkelijk toegenomen. Zo sterk zelfs dat migratie als normaal menselijk verschijnsel wel eens op de achtergrond lijkt te verdwijnen. De sterke link met debatten over veiligheid heeft deels 
te maken met het feit dat veiligheidskwesties sowieso meer in andere beleidsvelden doordringen, maar ook met het hoge aantal internationale migranten. Vooral irreguliere of illegale migranten trekken de aandacht, evenals degenen die geld verdienen aan deze vormen van niet-toegestane migratie: de smokkelaars, de handelaren, de werkgevers en inleners. Radicalisering en terrorisme en de betrokkenheid van personen met een migratieachtergrond daarbij hebben de associatie alleen maar versterkt.

Deze 'securitisering van migratie' leidt ertoe dat een groot aantal wetten en regels is en wordt ingevoerd om de veiligheid te bewaren en bewaken. Te denken is aan extra toezicht met ruimere wettelijke marges, detentie en uitzetting, het ontnemen van een verblijfsstatus of een (tweede) paspoort, maar ook aan strakkere restricties op migratielegalisering en naturalisatie. Migratiebeleid en criminaliteitsbeleid zijn door elkaar gaan lopen, ook wel aangeduid als crimmigratie (Guia, Van der Woude \& Van der Leun, 2010). Onbedoeld leiden deze beleidsinspanningen ook tot een verergering van de problematiek. Wie niet legaal kan migreren, gaat eerder illegaal en zal ook eerder in handen worden gedreven van profiteurs of zelfs uitbuiters. Door dit hele proces heen speelt de publieke opinie eveneens een rol. Deels worden de maatregelen ingevoerd vanwege de angst voor migratie en buitenstaanders, deels werken ze die perceptie in de hand, wat te zien is in de media, het publieke debat en het politieke debat. Veel mensen hebben het idee dat dit soort vraagstukken niet openlijk besproken kan worden, anderen ergeren zich aan het feit dat alles wordt geproblematiseerd zodra er een link is met migratie. Het thema migratie en veiligheid is duidelijk vol van paradoxen en vicieuze cirkels. Hoe staat het eigenlijk met het onderzoek hiernaar?

\section{Onderzoek}

Onderzoeken naar migranten en criminaliteit liggen gevoelig en laten geen eenduidig beeld zien. De relatie tussen criminaliteit, migratie en etniciteit wordt in Nederland al jarenlang en op diverse wijzen onderzocht. Het criminologische en (rechts)sociologische onderzoek rondom veiligheidsvraagstukken heeft zich tot nu toe vooral gericht op criminaliteit van en door min of meer gevestigde etnische minderheidsgroepen. Het veranderen van de Nederlandse bevolking heeft echter consequenties voor vraagstukken op het terrein van criminaliteit en veiligheid. Individuen met een migratieachtergrond zien zich uiteraard voor een belangrijk deel geconfronteerd met dezelfde vormen van dader- en slachtofferschap als autochtonen (Korf \& Bovenkerk, 2007). Zo zoeken niet alleen autochtone pubers door het plegen van kleine criminaliteit de grenzen van het betamelijke op. Jeugdigen van Marokkaanse of Turkse komaf kennen dergelijk 'kick-gedrag' eveneens. Dat is op zich niet opzienbarend en er zijn meer overeenkomsten te vinden. Zo beschrijven Bervoets en Stol (2002) dat er weliswaar scheidslijnen in de wijk zijn, maar dat Marokkaanse en autochtone Nederlanders in vergelijkbare mate zich in de wijk (on)veilig voelen. Ze stellen dezelfde buurtproblemen voorop. Over dat slachtofferschap van reguliere criminaliteit komen we overigens maar relatief 
weinig te weten op basis van de literatuur. Wel is er de laatste jaren meer aandacht voor studies omtrent mensensmokkel en mensenhandel en de relatie met migratie. Verder zijn er uitingen van criminaliteit, waarbij de culturele achtergrond van mensen met een migratieachtergrond een belangrijke factor van invloed kan zijn. Dat speelt bijvoorbeeld bij gewelddadige eerkwesties, waarbij burgers eigen rechter gaan spelen om hun gekrenkte eergevoel te herstellen (Janssen, 2008). De laatste tijd wordt ook vaker een verband gelegd tussen processen van radicalisering en migratie. ${ }^{1}$ Daarnaast kunnen migranten en hun nakomelingen zowel in actieve als in passieve zin te maken krijgen met vormen van intolerantie en discriminatie (Bovenkerk, Gras \& Ramsoedh, 1995). Het is dus te simpel om te stellen dat met de instroom van nieuwe groepen in de samenleving de problematiek van criminaliteit en onveiligheid is toegenomen. Het beeld van deze op zichzelf al ingewikkelde fenomenen met structurele en culturele invloeden, is wel complexer geworden (Bovenkerk \& Yeşilgöz, 2003; Janssen, 2011).

Studies naar al langere tijd in Nederland gevestigde groepen wijzen stelselmatig op een oververtegenwoordiging van Surinamers en Molukkers (oudere studies) en van Marokkanen, Turken en Antillianen (in meer recente studies) in de geregistreerde criminaliteit. Als we ook de tweede generatie meerekenen, zien we bij sommige groepen een duidelijke oververtegenwoordiging in de verschillende fasen van het strafrechtelijk systeem (Engbersen, Van der Leun \& De Boom, 2007). Na de millenniumwisseling verschenen de eerste cijfers over 'nieuwe' etnische groepen, met name uit asiellanden (o.a. Kromhout \& Van San, 2003). Ook kwam er gaandeweg meer aandacht voor irreguliere migranten en criminaliteit (zie o.a. Leerkes, 2007; Leerkes, Engbersen \& Van der Leun, 2012). Vooral op grond van dit soort studies naar de cijfermatige oververtegenwoordiging (en soms ondervertegenwoordiging) in de geregistreerde criminaliteit van verschillende etnische groepen, wordt het Nederlandse onderzoek op het terrein als geheel in Crime and Justice in the Netherlands (Tonry \& Bijleveld, 2007, p. 23) aangeduid als 'reasonably ample and impressively vibrant'. Een vergelijkbare kwalificatie gaven de redacteuren ook aan het onderzoek naar georganiseerde misdaad, waarin ook de rol van migranten opvallend is. Bovenkerk - een van de pioniers op dit terrein - twijfelt er niet aan dat Nederland op dit punt in Europa vooroploopt (Bovenkerk, 2007). Desondanks wordt de onderzoeksthematiek toch ook vaak nog geduid als taboe, mede omdat er sterk gepolariseerd op wordt gereageerd. Over de vraag in hoeverre relatief hoge criminaliteitscijfers vooral of mede worden bepaald door selectief optreden van politie en justitie wordt hevig gedebatteerd. Een onderwerp als etnisch profileren roept sterke emoties op en wordt al snel in de sfeer van 'erkennen of ontkennen' besproken (Van der Woude \& Van der Leun, 2013; Van der Leun, Van der Woude, Vijverberg, Vrijhoef \& Leupen, 2014). Als we dit positief willen duiden, kunnen we ook constateren dat er in ieder geval toegenomen aandacht voor en discussie over is. 


\section{Van migrantengroepen naar super-diversiteit}

Tot nu toe hebben we in deze inleiding gesproken over groepen migranten. Veel onderzoek doet dat ook. Van oudsher gaat de aandacht daarbij uit naar de klassieke grote migrantengroepen en hun nazaten. Maar de antropoloog Vertovec komt op basis van zijn analyse van migratie naar het Verenigd Koninkrijk (VK) dat er inmiddels in westerse samenlevingen sprake is van super-diversity. Dit concept biedt een nieuw perspectief op het nadenken over gevolgen van migratie dat naar inzien van de redactie meer aandacht zou mogen krijgen. Aan het einde van de vorige eeuw kwamen er niet alleen op grotere schaal migranten binnen, ze kwamen ook uit andere streken dan de al bekende arbeidsmigranten en migranten uit voormalige koloniën en landen van het Gemenebest. Deze nieuwe migranten brachten een grote verscheidenheid aan onder meer talen en religieuze opvattingen mee. Ook lieten de nieuwkomers veel diversiteit zien wat betreft de manier waarop ze naar het VK migreerden en hun legale status in het gastland: er kwamen migranten binnen met een visum om te werken, anderen om te studeren, weer anderen reisden af naar het VK om zich bij hun partner of familieleden te voegen en dan waren er nog asielzoekers en vluchtelingen. Sommigen kwamen legaal het land in, maar bleven langer dan toegestaan en anderen verbleven van meet af aan illegaal in het VK. En dan waren er nog de gelukkigen die volwaardig burger zijn geworden van de Britse samenleving. Ten gevolge van deze gevarieerde migratiestromen is een buitengewoon bonte samenleving ontstaan. Een belangrijk kenmerk van die super-diversity is dat die bontheid niet alleen een karakteristiek is van de samenleving in zijn geheel. Integendeel, een grote mate van sociaaleconomische verscheidenheid is ook waarneembaar binnen etnische groepen (Vertovec, 2007a, 2007b). Besef van deze notie van onderlinge en interne verscheidenheid is in veel onderzoek nog niet expliciet uitgewerkt. Om een voorbeeld te geven: in veel onderzoek naar en discussies over etnisch profileren wordt de suggestie gewekt dat we het hebben over personen met een witte en personen met een donkere huidskleur. De werkelijkheid is een volstrekt andere. Ook als we studies over de oververtegenwoordiging van migranten in de geregistreerde criminaliteit vergelijken met de complexe realiteit van groepen, generaties, gemengde identiteiten en - dat kunnen we toevoegen aan de super-diversiteit - het brede palet aan legale statussen met afgepaste rechten voor migranten ontstaat er een veel gemengder en genuanceerder beeld. Het verdisconteren van deze ruime mate aan variatie in achtergronden van migranten en hun positie in de samenleving maakt verder onderzoek naar de relatie tussen migratie en veiligheid allesbehalve eenvoudiger.

\section{Dit themanummer}

Voor de gastredactie van het Tijdschrift voor Veiligheid is een belangrijke vraag of het beschouwen van migratie als veiligheidsvraagstuk ook leidt tot de meest effectieve aanpak van knelpunten en problemen. Een vraag waar we hier niet dieper op ingaan, is wat theoretisch gezien de rationale is achter het onderzoeken 
van migratie in relatie tot veiligheid. Waarom wordt dit verband zo snel en graag gelegd? Een van de problemen is dat het debat nogal eens in heel algemene termen wordt gevoerd, terwijl onderzoek laat zien dat we gezien de complexiteit algemene uitspraken moeten overstijgen en veel specifieker dienen te kijken om te weten wat (a) verklaringen kunnen zijn en (b) in welke richting we moeten denken om een effectieve aanpak te ontwikkelen (zie ook hierboven). Ten tweede wordt met de aandacht voor de publieke veiligheid de kant van menselijke veiligheid wel eens uit het oog verloren. Wat maken asielzoekers mee onderweg en tijdens hun verblijf in Nederland? Hoe staat het dan met de veiligheid? Ten derde is duidelijk dat het vraagstuk naar de relatie tussen veiligheid en migratie niet los kan worden gezien van de wijze waarop er over in de samenleving wordt gesproken en geschreven en welke beeldvorming er is.

Het voorliggende themanummer brengt een aantal actuele onderzoeken bijeen die aandacht besteden aan zowel migratie en veiligheidsvraagstukken als het debat daarover.

Sacha van der Velden beschrijft de werkwijze van smokkelaars van Syrische migranten naar Nederland; vanwege de oorlog in Syrië een omvangrijke categorie asielzoekers die veelal gebruikmaakt van mensensmokkelaars. Op basis van relevante documenten en literatuur wordt een beeld geschetst van de manier waarop smokkelaars samenwerken, de smokkelroutes en de te onderscheiden functies van de smokkelaar in het mensensmokkelproces, zoals de ronselaar, de organisator, de chauffeur, maar ook de rol van legale bedrijven. De reis die Syrische vluchtelingen maken vanuit het Midden-Oosten naar Europa en de rol van mensensmokkelaars daarin blijkt erg divers en veranderlijk. De auteur wijst op het belang van een meer humane aanpak van de vluchtelingenproblematiek, waarbij vluchtelingen meer legale mogelijkheden worden geboden om te vluchten en smokkelaars effectief aangepakt worden.

Desiree Horbach en Conny Rijken gaan in op de veiligheid van een andere specifieke groep asielmigranten: Eritreeërs in Nederland. Op basis van eigen onderzoek en empirische data uit een verkennend onderzoek in de asielopvang in Nederland laten zij zien dat betrokkenen die met Eritreeërs werken veel zorgen hebben over de afhankelijkheid en mogelijke uitbuiting van de asielzoekers en statushouders. Deze zorgen zijn vaak verweven met religieuze en traditionele rituelen die moeilijk zijn te duiden voor buitenstaanders. Tegelijkertijd wordt geconstateerd dat onder Eritreeërs angst heerst voor de invloed van de orthodoxe kerk en de lange arm van het Eritrese regime. Een aantal zorgen kan worden gekwalificeerd als mogelijk signaal van mensenhandel. In combinatie met laaggeletterdheid, een laag opleidingsniveau en gebrekkige verbindingen met de ontvangende samenleving komen serieuze belemmeringen naar voren bij de integratie in Nederland. De auteurs roepen op deze groep intensief te begeleiden. De ondersteuning dient gericht te zijn op vermindering van de kwetsbaarheid, vergroten van de bewustwording van (toekomstige) uitdagingen en risico's, empowerment en educatieve trainingen, en vangt idealiter aan tijdens de COA-opvang, voordat woonruimte in een gemeente wordt toegewezen. 
Joris van Wijk en Maarten Bolhuis gaan in hun artikel in op de zogenoemde 1F-problematiek. Met deze wat technische aanduiding wordt gedoeld op pogingen van de overheid om de veiligheid in de asielmigratie te beschermen. De bedoeling is om te zorgen dat oorlogsmisdadigers, criminelen en terroristen geen verblijfsstatus krijgen of dat deze hun wordt ontnomen. In het artikel beschrijven ze de juridische grondslag, de signalering en wat we weten over de aard en omvang van deze groep. De auteurs concluderen dat het identificeren van vermeende oorlogsmisdadigers en jihadisten bijzonder complex is en dat er een spanningsveld is met betrekking tot nut, noodzaak en wenselijkheid van het beschikbaar stellen van concrete handvatten in de vorm van indicatoren(lijsten) aan eerstelijnsprofessionals om jihadisten te herkennen. Met het oog op het doel van een veiliger samenleving stellen de auteurs enigszins contra-intuïtief voor om ongewenst verklaarde, maar niet uitzetbare (criminele) asielzoekers onder bepaalde voorwaarden een tijdelijke verblijfstatus te verschaffen.

Janine Janssen en Ruth Sanberg staan stil bij het gegeven dat een deel van de asielzoekers in Nederland afkomstig is uit landen waarin eercodes en daaraan gekoppelde opvattingen over het gebruik van geweld uit naam van de familie-eer niet onbekend zijn. Er is in Nederland echter nooit onderzoek gedaan naar eeropvattingen onder asielzoekers en de eventuele import van conflicten. Om toch iets meer te weten te komen over geweld in naam van eer onder deze specifieke groep hebben zij een verkennend onderzoek uitgevoerd op basis van dossiers van het Landelijk Expertise Centrum Eer Gerelateerd Geweld van de nationale politie. Wat wordt in die dossiers aangetroffen en welke mogelijkheden en beperkingen biedt dit soort politiële informatie? Op basis van deze verkenning komen zij tot een voorzet voor vervolgonderzoek.

Jelmer Brouwer, Maartje van der Woude en Joanne van der Leun onderzochten het aspect veiligheid in migratiecontroles achter de grenzen middels het Mobiel Toezicht Veiligheid. De mobiele identiteitscontroles uitgevoerd door de Koninklijke Marechaussee in de Nederlandse grensgebieden kennen een complexe wettelijke en beleidsmatige grondslag. Het vreemdelingrechtelijk toezicht is vervlochten met enkele vormen van strafrechtelijke handhaving. De resultaten laten zien dat marechaussees enerzijds doordrongen zijn van hun taak in de migratiecontrole, maar anderzijds ook het vangen van 'boeven' als een belangrijk onderdeel van hun taak zien. Daarbij maken ze deels op creatieve wijze gebruik van hun ruime bevoegdheden om dat doel te bereiken. Dit heeft gevolgen voor de transparantie van beslissingen en voor de rechtspositie van personen die zich al dan niet als migrant in grensgebieden bevinden. De auteurs concluderen dat fundamentele afwegingen op dit punt wel erg worden overgelaten aan het niveau van de uitvoering.

Marnix Eysink Smeets \& Anoek Boot kijken naar de publieke opinie en beeldvorming. Wat zijn nu de publieke zorgen rond de instroom van vluchtelingen in Nederland in relatie tot veiligheid? Het verkennende onderzoek laat zien dat de zorgen over de instroom divers zijn en slechts ten dele gerechtvaardigd worden door daadwerkelijk te verwachten problemen. 'Mismatches' tussen beelden en 
geobserveerde ontwikkelingen laten zich vermoedelijk verklaren door dezelfde vertekenende mechanismen die eerder in algemenere studies op het gebied van veiligheidspercepties zijn beschreven. De zorgen raken aan een breed palet van meer generieke zorgen en ongenoegens in de samenleving. Het is daarom van groot belang dat de overheid de zorgen serieus neemt en er met een heldere en realistische langetermijnvisie op migratie op reageert.

\section{Tot slot}

Uiteindelijk is de vraag wat een effectief beleid is ten aanzien van migranten en veiligheid natuurlijk uitermate complex. De bijdragen tezamen laten zien dat het zinnig is de verschillende aspecten van veiligheid in samenhang te beschouwen, zonder daarmee de suggestie te wekken dat migratie an sich problematisch moet zijn. Een effectief beleid heeft rekening te houden met de beeldvorming en de zorgen van de bevolking. Een heldere visie vanuit de overheid met ook oog voor de onmogelijkheden van beleid kan daaraan bijdragen. Ten tweede is de veiligheid van degenen die in Nederland bescherming zoeken niet zonder meer gegeven als zij naar Nederland komen en asiel verkrijgen. De voorbeelden van de tocht naar Nederland met hulp van mensensmokkelaars en de geobserveerde onvrijheid van een deel van asielzoekers vergt stevige beleidsaandacht om te zorgen dat uiteindelijk niet hun integratie in Nederland moeizaam wordt. Investeren in integratiebeleid vraagt een lange adem, maar wel een die uiteindelijk meer oplevert dan het blijven focussen op de eerste opvang. Ten derde laat dit themanummer zien dat in de moeizame samenhang van migratiebeleid en criminaliteitsbeleid de veiligheid soms gebaat kan zijn bij het maken van keuzes die vanuit migratiebeleid gezien onaantrekkelijk lijken of als minder acuut worden gezien. Ook dat vergt keuzes die duidelijk zouden kunnen worden uitgelegd juist op basis van het doel van een veiliger samenleving, ook en misschien wel juist in tijden van super-diversiteit.

\section{Literatuur}

Bervoets, E. \& W. Stol (2002) Marokkanen en Nederlanders over hun wijk - gedeelde problemen als mogelijkheid voor buurtactivisme. Tijdschrift voor Criminologie, (3), 247-261.

Bovenkerk, F. (2007) Een taboe op de criminologische verklaringen van misdaad?. In A. Soeteman \& F. van den Born (red.), De ethiek van sociaalwetenschappelijk onderzoek. Amsterdam: KNAW, 9-16.

Bovenkerk, F., M.J.I. Gras \& D. Ramsoedh (1995) Discrimination against migrant workers and ethnic minorities in access to employment in the Netherlands. Genève: International Labour Organisation.

Bovenkerk, F. \& Y. Yeşilgöz (2003) Nieuwe strafrechtsproblemen in Nederland. In F. Bovenkerk, M. Komen \& Y. Yeşilgöz (red.), Multiculturaliteit in de strafrechtspleging, Den Haag: Boom Juridische uitgevers, 1-27.

Engbersen, G., J. van der Leun \& J. de Boom (2007) The Fragmentation of Migration and Crime. Crime and Justice, 35(1), 389-452. 
Guia M.J., M.A.H. van der Woude \& J.P. van der Leun (red.) (2012) Social Control and Justice: Crimmigration in the Age of Fear. Den Haag: Eleven International Publishing.

Janssen, J. (2008) Je eer of je leven? Een verkenning van eerzaken voor politieambtenaren en andere professionals (tweede herziene druk). Den Haag: Stapel \& De Koning.

Janssen, J. (2011) Schering en inslag. Enkele wenken voor politieambtenaren en andere professionals voor opbouw en onderhoud van netwerken in de multi-etnische samenleving. Den Haag: Boom Lemma Uitgevers.

Korf, D.J. \& F. Bovenkerk (2007) Dubbel de klos. Slachtofferschap van criminaliteit onder etnische minderheden, Den Haag: Boom Juridische uitgevers.

Kromhout, M. \& M. van San (2003) Schimmige werelden. Nieuwe etnische groepen en jeugdcriminaliteit. Den Haag: WODC/Boom Juridische uitgevers.

Leerkes, A. (2007) Illegaal verblijf en veiligheid in Nederland. Amsterdam.

Leerkes, A., G. Engbersen \& J.P. van der Leun (2012) Crime among irregular immigrants and the influence of internal border control, Crime, Law and Social Change, 12(1), 15-38.

Leun, J.P. van der, M.A.H. van der Woude, R.D. Vijverberg, R.P.M. Vrijhoef \& A.J. Leupen (2014) Etnisch profileren in Den Haag? Een verkennend onderzoek naar beslissingen en opvattingen op straat. Leiden: Universiteit Leiden.

Tonry, M. \& C. Bijleveld (Eds.) (2007) Crime and justice in the Netherlands (Crime and Justice, An Annual Review 35). Chicago: The University of Chicago Press.

Tubergen, F.A. van (2012) De angstmens en zijn vijanden: Feiten en fabels over de integratie in Nederland. In G. van Stralen \& R. Gude (red.), ... En denken! Bildung voor leraren. Leusden: ISVW Uitgevers, 187-194.

Vertovec, S. (2007a), New Complexities of Cohesion in Britain: Super-Diversity, Transnationalism and Civil-Integration. Commission on Integration and Cohesion.

Vertovec, S. (2007b) Super-Diversity and its Implications. Ethnic and Racial Studies, 30(6), 1024-1054.

Woude, M.A.H. van der \& J.P. van der Leun (2013) De Nederlandse veiligheidscultuur als katalysator voor etnisch profileren?. Tijdschrift over Cultuur en Criminaliteit, 3(2), 123-136. 